\title{
Use of Ohmmeter for Detection of Leak in Hydraulic Penile Prostheses: A Case Report
}

\author{
Luis Barragan, MD, MCE*; Irving J. Fishman, MDCM , FRCS(C), FACS* \\ Department of Urology, Baylor College of Medicine, Houston, Texas, USA \\ ${ }^{*}$ Corresponding author \\ Irving J. Fishman, MDCM , FRCS(C), FACS \\ Urologist, Department of Urology, Baylor College of Medicine, Houston, Texas, USA; E-mail: irving.fishman@va.gov
}

\section{Article Information}

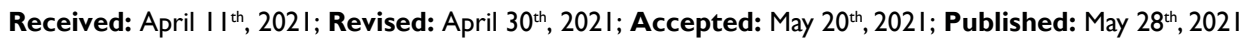

\section{Cite this article}

Barragan L, Fishman IJ. Use of ohmmeter for detection of leak in hydraulic penile prostheses:A case report. Urol Androl Open J. 202I; 5(I): I5- I6. doi: 10.17I40/UAOJ-5-139

\section{INTRODUCTION}

$\mathrm{H}$ ydraulic urinary prostheses have generally been accepted as important treatments for erectile dysfunction and urinary incontinence. Complications of these devices are usually treated with replacement if they fail after 5-years, based on the recommendations of their manufacturer. However, if devices fail prior to that time, the source of the defect must be localized so that the defective component can be identified and replaced. The following case demonstrates such a situation.

\section{CASE REPORT}

A 67-year-old male with a history of robot-assisted laparoscopic prostatectomy and bilateral lymph node dissection presented with progressive erectile dysfunction post-operatively. He failed to respond to conservative therapy and underwent implantation of an American Medical Service (AMS) 700 inflatable penile prosthesis (IPP) approximately 2-years ago. The patient indicated that the device had worked well for one year but then noted that he had to pump his inflatable prosthesis multiple times and could never obtain an erection as rigid as that achieved initially. Eventually, the patient noted that the pump went flat after about 5 compressions. He denied any fever or chills or pains in his abdomen.

After medical clearance we proceeded to access the penile tubing via the original penoscrotal incision. Once the silicon tubing to both cylinders and the reservoir were located, we used an ohmmeter to find the leak. The tubing appeared to be intact so we accessed the connectors of the tubing of the IPP. After testing, each of the components it was determined that the leak was in the reservoir. It was mobilized via a transverse incision in the left lower quadrant where the reservoir was located. The tubing helped us track location of the reservoir by slight traction on the reservoir itself. Once it was localized, the reservoir which held $65 \mathrm{~mL}$ was mobilized from its capsule and removed. A new $65 \mathrm{~mL}$ reservoir was introduced in the existent capsule and filled with $65 \mathrm{~mL}$ of normal saline. The tubing from the new reservoir was then tracked to the pump for connection using a modified knitting needle. After the other components were flushed with fresh normal saline, new connections were made between the pump and the reservoir. Redundant tubing was then removed and a quick connector was used to reconnect the system. The pump was then cycled and the IPP provided an excellent erection. The wounds were then closed in 2 layers using 3-0 polydioxanone suture (PDS) and monocryl for the subcutaneous layer. The patient was discharged home the same day.

\section{DISCUSSION}

Hydraulic urinary prostheses have been accepted as effective treatments for urinary incontinence and erectile dysfunction since 1973. When there is an IPP or artificial urinary sphincter (AUS) malfunction, urologists need to repair or replace them. The most common failure is due to loss of fluid from the system with loss of function. In the late 70 s Dr. F. B. Scott, with the help of an electrical engineering medical student, realized that an ohmmeter can be used to localize the leak without replacing the whole device.

The concept is self-evident when we think of the prostheses as an electro-conductive device filled with normal saline and placed within a body which is also electro-conductive. The silicon of the prostheses prevents communication of the prosthesis fluid with that of the body fluid. If there is an interruption in the continuity of the silicon there is a leak. By placing electric leads attached to the inside of the prostheses and the body, one can detect with an ohmmeter whether there is current flowing between these leads. If there is a significant deflection in the ohmmeter then we can confirm the leak and replace the component that is defective. This is further illustrated in the following illustrations (Figures 1-3). 


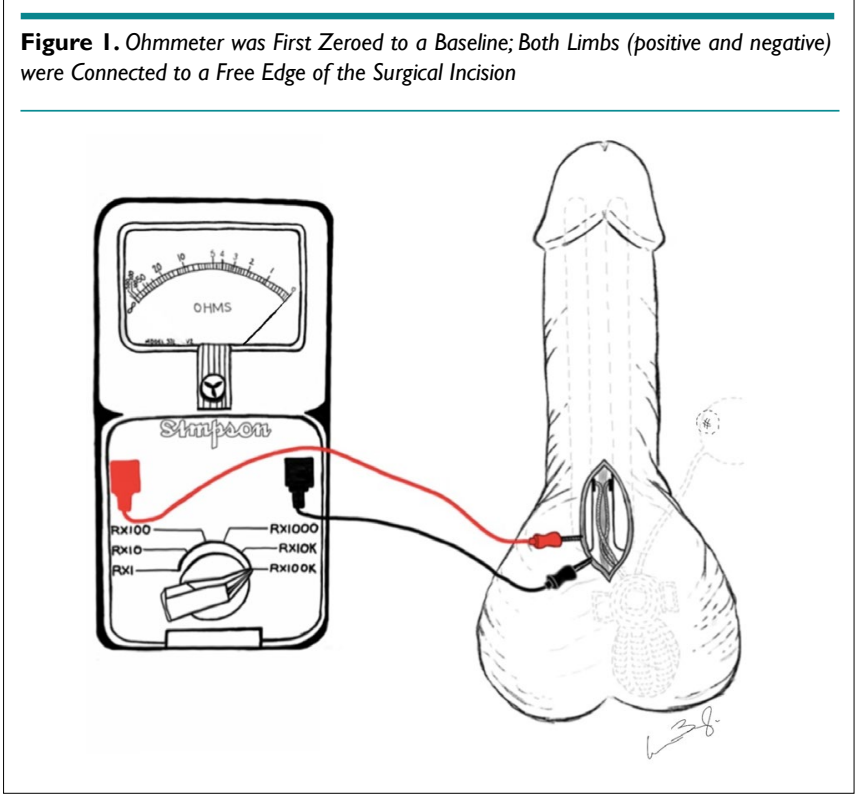

Figure 3. Right IPP Cylinder Assessment; Both Limbs were Connected to the Ohmmeter, Negative Limb Clamped to the Edge of the Surgical Incision and Positive Limb Clamped to the Blunt Metal Needle, Pressure to the Syringe Embolus was Added and Ohmmeter showed a Finite Resistance Confirming Leakage

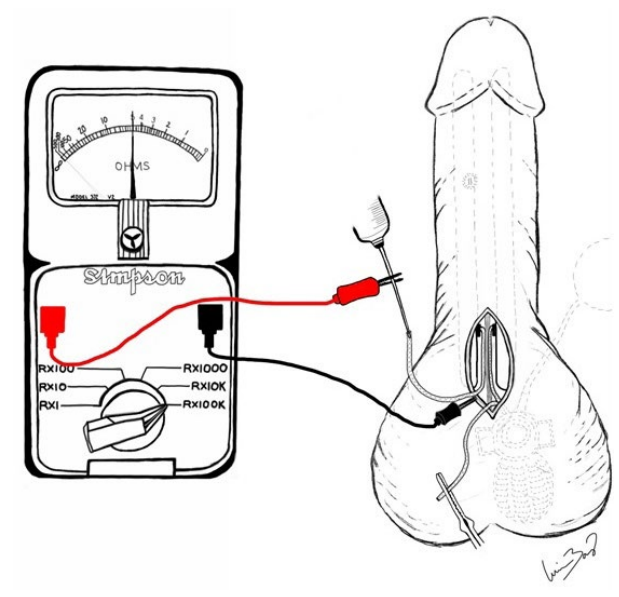

In an article by Sleph et $a 1,{ }^{1}$ he assessed the ohmmeter for leakage in the IPP and AUS and found 75 to $100 \%$ sensitivity to identification of the correct site of the leak. In a total of twenty surgeries in nineteen patients, he correctly identified the location of fluid loss in eighteen of twenty patients, 90\%. Other researchers such as, Webster et $\mathrm{al}^{2}$ have found similar results using this technique.

\section{CONCLUSION}

The advantage of testing with an ohmmeter is that it has the poten-
Figure 2. Left IPP Cylinder Assessment; Both Limbs were Connected to the Ohmmeter, Negative Limb Clamped to the Edge of the Surgical Incision and Positive Limb Clamped to the Blunt Metal Needle to Asses Circuit Integrity

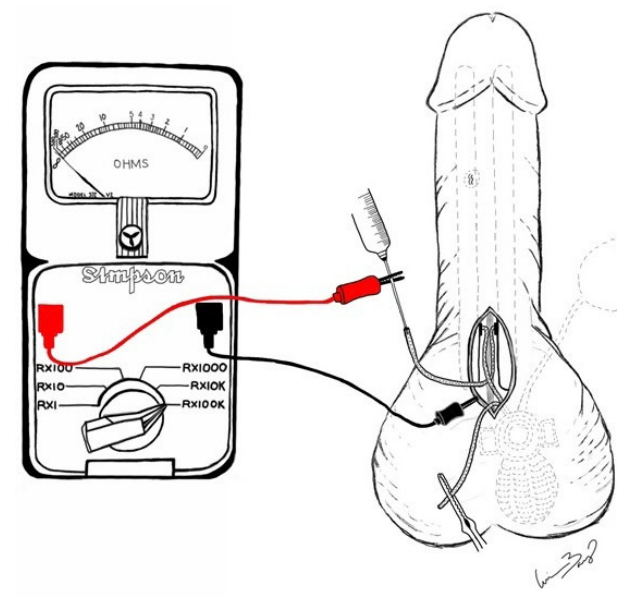

tial to decrease the extent and duration of surgical repair. By decreasing the amount of dissection that has to be done, there is less chance of exposure of tissues to infection. Use of an ohmmeter is a simple and inexpensive means of evaluating integrity of the silicon sheathed device.

\section{FUNDING}

There are no funding sources.

\section{CONSENT}

The authors have received written informed consent from the patient.

\section{CONFLICTS OF INTEREST}

The authors declare that they have no conflicts of interest.

\section{REFERENCES}

1. Selph JP, Belsante MJ, Gupta S, Ajay D, Lentz A, Webster G, et al The ohmmeter identifies the site of fluid leakage during artificial urinary sphincter revision surgery. J Urol. 2015; 194(4): 1043-1048. doi: $10.1016 /$ j.juro.2015.05.075

2. Webster GD, Sihelnik SA. Troubleshooting the malfunctioning Scott artificial urinary sphincter. J Urol. 1984; 131(2): 269-272. doi: 10.1016/s0022-5347(17)50343-2 